\title{
Susann Vihma
}

\section{Design as Language - a Misconception?}

\begin{abstract}
Because design is often conceived of as a language, it is worthwhile to take a closer look at this relationship. It is especially interesting to look at the transition from the verbal to the visual in interpretations and analyses of design. This article discusses some salient topics appearing in this context. In particular, claims made in the books by Kress and van Leeuwen (1996) and Krippendorff (2006) are discussed, because their approaches are widely used in design discourses, in journals, schools, exhibition catalogues, etc. These texts probably influence design research, but, in the present author's view, do not help interpretation of visual qualities in design. The underlying critical assumption in this article is that the language metaphor and concepts derived from linguistics do not do justice to the interpretations of design objects, especially concerning their visual qualities. When these qualities are underrated, it seems difficult to assess the cultural significance of design.
\end{abstract}

Keywords: visual design, language, text, reading, image

\section{Introduction}

Design is evolving in terms of planning and making as practices. Various questions concerning its aims, bases, connections, qualities, values, and so on form its theoretical discourse. In order to develop a discourse, suitable concepts have been sought in several disciplines, such as philosophy, information theory, psychology, sociology, linguistics, literary studies, and semiotics. Sometimes the adopted concepts and theories seem successful, at other times these are less fruitful. One usual tendency has been to modify the concept of language to make it fit topics of visual imagery and visual design. This is not surprising. Design theory has to look for suitable theoretical frameworks and conceptual foundations, and design theory touches a diverse set of approaches. The present article will focus on visual qualities in product design and in the design of the built environment, and thus leaves, for instance, service design aside, though even that branch makes use of visual presentations.

Indeed, the design world and its agents have developed a discourse within the various professional practices, in companies and educational institutions. However, it seems that not much is being generated from this tradition; it does not encourage design theory and criticism. This may be due to the fact that design has been conceived of as a practical trade, consisting of planning concrete material products in single projects. On the other hand, design talk has been moving into its neighboring fields, into marketing and business strategies, mass communication, and so on. Thirdly, design thinking and discourse have been influenced by technological and economic constraints, ergonomic possibilities, users' acceptance, and other issues more than by internal intellectual reflection. In this article, however, my main concern is that design theory and discourse are often dominated by linguistics, by the language metaphor in particular. Design is analyzed as if it would be a language-like system. As a result, the visual and its specific signification easily fade from view (Fig. 1). 


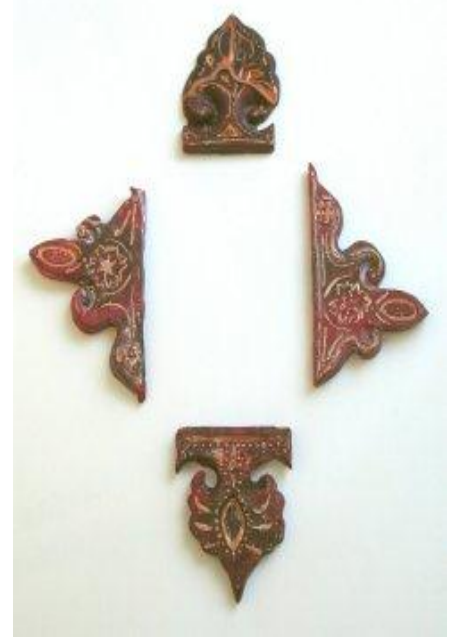

Figure 1. When we look at something as a text, it can lose its peculiar visual characteristics; the visual qualities of the perceived entity may disappear. This is also a concern when we interpret the visual qualities of a design object. Language provides a frame for interpretation, a narrative - but this is not enough. My claim is illustrated by the art work Indian Reliefs by Outi Turpeinen, 2003 (photo by Outi Turpeinen).

That is why it seems important to look closer at the topic: design conceived as language. By language I refer to verbal language scrutinized by linguistics. Often, the platform for looking at design is situated in linguistics, and the study of the relationship is based on the idea of language. There is a tradition of conceiving "design as language" in design history. However, to my knowledge, no survey has been carried out on the topic yet. An early discussion stems from Vienna in the late $19^{\text {th }}$ and early $20^{\text {th }}$ century. The Danish scholar Anders Munch (2003) has thoroughly investigated these discussions, which included many prominent personalities in different fields, such as Adolf Loos, Ludwig Wittgenstein, and Arnold Schönberg. Questions concerning new forms of expression were burning issues. It seems that the philosophy of language influenced ideals in visual design. Designers and architects wrote about their aims, and parallels can often be shown with the ideas concerning language. Much later, when design semantics became a hot topic in the 1980s, Jochen Gros (1983) developed a design theory using a verbal language reference. All in all, design as language is not a new concept, as can be seen in the design history documents.

Nevertheless, there has not been sufficient theoretical argumentation to support the practical undertakings of design. By stating this, my intention is not to ignore earlier attempts to formulate design theories, say, from the beginning of modern Western design history in the late $19^{\text {th }}$ century. In this history, we have the writings of William Morris, the early modernists (as mentioned above), Tomás Maldonado, and others who have contributed to the discourse in the design field. More recently, many design researchers have developed design thinking and concepts and have published widely in international journals and conference papers. Design has entered the academia. Doctoral programs resulting in theses have consolidated its position as a discipline. All this is probably very well known, and accepted as progress in the field.

In spite of all this, some problematic issues pop up repeatedly, when conceptions of form and visual quality, methods as well as frameworks are adopted from more elaborated disciplines or from those that somehow seem related. For their analyses of visual form, design theories have often borrowed from linguistics and literary studies, which is the particular concern in this article. Design is conceived as language-like communication, and when models are created in order to understand functions and cultural signification, design is considered in them as a verbal message, telling a story, constructed as a text, and so on. This gives rise to the question of how the one can be translated into the other. Is the relationship "design as language" clear at all? This paper will, therefore, start to look closer at the following questions:

How is design conceived of as being language-like?

How does design resemble a text? 
Why is the language metaphor so popular in design discourses?

What are the benefits and disadvantages of this metaphor for design discourse and design?

To answer these questions, I will make use of two sources which are widely used in design writing and education. With the help of the chosen texts, I wish to point at some problems that occur by comparing design to language, and argue that important characteristics of visual design are lost. The first text belongs to so-called social semiotics as presented by Gunther Kress and Theo van Leeuwen from 1996. It exemplifies the use of the language metaphor, which will be illuminated below. A very different approach, and one more closely related to design theory, is presented by Klaus Krippendorff in his book on product semantics in 2006. Krippendorff (2006: 46) draws many parallels between language and design, asserting that artifacts are language in interaction. Later on in the text Krippendorff (p. 61) presents more correspondences between language and artifacts, such as design products. The book is very ambitious in that it aims to establish a new design theory. Hence, it is sometimes cursory, especially in relation to design history. Semiotics is presented at the end of the book, largely with erroneous conclusions and sometimes in an aggressive tone. The ontologies of Charles S. Peirce and Ferdinand de Saussure are grouped together. Polysemy is demonstrated with Bakhtin, but not mentioned explicitly (p. 276). The rich legacy of semiotic theories is credited incorrectly, and only a very few conceptions are touched upon, and those only in passing. Perhaps Krippendorff's concern with what is called semiotics is somewhat personal and stems from experiences in his studies at HfG Ulm in Germany (1965-61), surprisingly dealt with in in detail the end of the book.

A basic axiom of Krippendorff, one which deserves more discussion, is that we do not see and interact with the physical qualities of things, but with what they mean to us (pp. 47, 82, 87; see also clarification on p. 85 and the dualistic outlook illustrated in the figures). Meaning construction is primary, function comes second. Krippendorff claims that "twodimensional artifacts must be read just as three-dimensional ones are" (p. 208)(my italics).

The language metaphor is sometimes used in other disciplines when discussing design. For instance, in a sociological text (Shove, 2007: 7) it reads that "... the object says by means of its design." (my italics). The implication is that objects are talking to us, the users. To illustrate the object's saying, we might ask what is actually being said. Is someone listening? (Fig. 2). How or by what means does a product say something? Sometimes, design is seen as writing, and it is conceived as text. Over and over again, design is construed as having the form of language and of speaking.

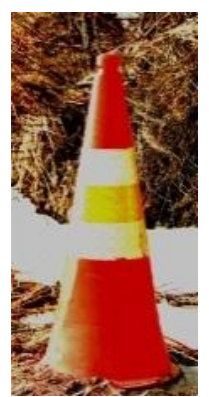

Figure 2. A traffic cone. What does it say? Can someone listen to its utterance? How does the cone, a plastic orange cone with yellow and white stripes, tell us through its material form that we should go round it to avoid some danger?

Krippendorff (2006: 117), too, illustrates the relationship with an example from traffic culture. Here, the colors of the traffic lights tell the drivers about crossing. Furthermore, Krippendorff sees a product as a system of character traits, one which is similar to verbal language. In his eclectic theory, in which language is a key concept, the meaning of artifacts is seen as embedded in narratives (pp. 169-174). Accordingly, a chair may afford sitting, but 
without a story it has no other significance. In his elaboration of narratives, Krippendorff is applying the concept of affordance as introduced by James J. Gibson.

\section{Points of Criticism}

In the following, I will examine the shortcomings of the use of the language metaphor by looking at some salient issues, which, in my view, underline a misconception. Coming back to Fig. 2. I would claim that, actually, the cone says nothing. Rather, it functions as a symbol in a system, in the paradigmatic system of relations to other traffic objects, which one must learn to interpret when one sees it. Furthermore, it functions on the basis of its visual quality and an agreement. Problems that follow, in my view, are that the visual and the actual meaning of materiality of any design, especially in product design and architecture, are given only little consideration. My reading of the two chosen books is largely informed by Göran Sonesson's (2003) criticism of the language metaphor, and by Altti Kuusamo's (1990) inquiry into the relationship between the word and the picture.

Verbal language and pictures have for a long time been regarded as a matter of different capacities for representing an event with respect to time. Sonesson $(2003: 4,7)$ relates that Lessing saw language as being able to relate the whole process of what is happening, whereas a picture (a painting or a sculpture) only shows a moment of what actually occurs. A picture presents objects in the story simultaneously, as in a scene; a verbal text has to deal with objects bit by bit, over a time span. With reference to Leonardo, Kuusamo (1990: 77) states that a painter can demonstrate the beauty of a person in a single moment, whereas the poet must show the same in a successive manner. Moreover, pictures (or sculptures) cannot show what happened in the past; they are doomed to the present, to the here and now. In this respect, design products are very much like pictures with respect to their visual form and functioning. Yet, because they are three-dimensional, they cannot be comprehended all at once. Additionally, design products need time for being touched and used before they can be interpreted as useful tools, which affects interpretation of their meaning. However, such qualities do not bring design objects closer to language.

The second problematic issue concerns intertextuality that is the claim that pictures do not refer to other pictures as much as verbal texts do by quoting earlier ones (Sonesson, 2003: 17). In their discussions of the matter, many scholars use examples from novels and poems, comparing them to images from art history. The examples may clarify their point, but also limit their claim to specific areas of verbal language and images. To my knowledge, intertextuality as form references has not been studied in the context of design research. Nevertheless, design history shows plenty of comments concerning influences and comparisons of visual characteristics in various objects. Modernism in design can be considered a network of visual references. Design objects often carry signs of history through their visual forms, but probably in a different manner than intertextuality in literature.

The third thematic issue in my criticism concerns the competence of pictures. Sonesson (2003: 22) points out that a picture cannot differentiate between a topic or a theme and what it says about it. It follows that the picture must be a statement at the very moment of its perception. By contrast, a verbal text can describe something first, and then take a stance later in the text. A design object seems to be a statement like the picture. Relating to this, it has been claimed that the pictorial system is open, whereas the verbal system of language is closed, because it is delimited by its grammar and lexicon. Nevertheless, in its openness a picture is subordinate to style, which means that we always have a particular kind of a horse, for example, whenever a horse is presented as a picture (or as a sculpture, or a toy). The same applies for design. There is a specific kind of coffee machine in the café, a specific way of functioning as a coffee machine, a specific style of the same, and so on. 
Fourthly, interpretation of pictures is compared to reading a verbal text from left to right. Sonesson explicitly criticizes Kress and van Leeuwen for their claims in their 1996 book. (However, it seems to me that van Leeuwen has modified his thinking later on in his 2005 book.) The key dimensions of the visual space are thought of as being influenced by writing from left to right (or from right to left in a different culture), or from top to bottom or vice versa, and these reading directions are taken for granted. Hence, the interpretation of visual composition would be guided by center and margin, top and bottom. Kress and van Leeuwen give an example of how a painting by Rembrandt, the Double Portrait of the Mennonite Preacher Cornelis Claesz. Anslo and His Wife, Aeltje Gerritsdr Schouten from 1641 (Steveartgallery), can be read by applying this method of reading images. According to them, one starts reading the painting from the left, proceeding to the right. During the process of reading, things remain on the left while the reading proceeds to the right. What is on the left is old; reading the painting proceeds towards what is new. Also the painter has organized the image accordingly: what is on the left is already given and old; the new is located on the right hand side. The light area on the left in this Rembrandt painting is interpreted as a given, and the darker area on the right is conceived as something new. And so the interpretation goes on, with the authors presenting their reading in detail (Kress and van Leeuwen, 1996: 199-202, 239-240). In my view, their interpretation is surely one option. But why would an interpretation proceed in this way (from left to right) in the first place? To what extent can an interpretation be construed from this left-right assumption, which would imply that things on the left in a picture are always given, and those on the right are always new? Is it plausible by virtue of the fact that the interpretation is derived from and similar to the process of reading written verbal language? An alternative method of interpretation could be to look at the painting and focus first on the face of the portrayed wife with her illuminated face on the right, and then continue by looking at the lighted area on the left and the other face in the middle of the painting, back and forth.

Even more obvious is Kress and van Leeuwen's (1996) ease of argument for reading pictures accordingly in their example of Nicholson's abstract painting. The painting shows two circles. Because one of them is on the left side, it is conceived as given and unsemiotized; accordingly, the other one is unproblematically interpreted as semiotized and new. Other examples, such as the one concerning Sisley's painting, do not seem to hold water either, because we can find pictures by the same painter with an almost contrary composition. A similar generalization is made with reference to Monet's painting too. Being threedimensional material things and spaces, design objects can hardly follow a one-way linear reading manner, from left to right.

Lastly, it is said that pictures are unable to negate, because they make positive statements of what is. Pictures cannot say 'no' according to Kuusamo (1990: 78). A pictorial composition can be thought of as a report. However, in my view, we do not perceive images only as manifestations of events in the here and now. The process of interpretation involves many non-visual issues, such as values, memories, emotions, habits. This is why the question of negation seems more complex. A design object can possibly be interpreted as being able of negation when its function is disguised. The form may embody a non-perceivable technical construction, or it may refer to something that has no bearing at all on the practical functioning of the object. Negation of form by three-dimensional design objects could be an important topic for design research. Here, I have only briefly presented the topic as a case of the misconception.

As pointed out above, all five thematic issues can be transposed to apply to design objects and the outcomes of design processes, at least insofar as their visual aspects are concerned. Of course, design products also involve other important points of view that influence their visual 
perception and, furthermore, how they are represented in language and other media. For the purposes of this article, however, I have limited myself to visual qualities.

\section{Language First?}

In an essay from 1986, Kuusamo (1990: 73-74) compares verbal and pictorial representations of the world. He writes about the age-old rivalry between these two modes, concluding that it is futile. He points out that many scholars, especially some so-called postmodern philosophers, have given primacy to verbal language. This tradition is strong in the history of semiotics, as in the theories developed by Juri Lotman, who expanded the concept of text to film, painting, and even symphonies (in design research, see also Krippendorff 2006: 151). Kuusamo also asks how a word (or a sentence) semiotically differs from or is akin to a picture. From an art history point of view, he claims that modernism has widened to the utmost the gap between the two modes of representation. Pictures used to serve symbols, religious ones mostly, and pictures were created at the mercy of those symbols, such as represented in the Bible. In spite of such conditions, artistic expression was renewed again and again. Nowadays, the dominance of narrative and literary symbols has dissolved. The quotation by Baudrillard (2003: 2) clearly illuminates what is at stake, when we approach the different modes:

The concept is unrepresentable, but the image is inexplicable. Between them is, then, an insuperable distance. As a result, the image is always nostalgic for the text and the text nostalgic for the image. (Baudrillard, 2003: 2)

Even today, contemporary culture carries much of the legacy of the old relationship between the verbal and pictorial. Because a picture is compared to and even conceived of as text (although of a different kind), one recurring issue is the attempt to define the smallest visual unit. However, a patch of color (in a picture) does not possess the double articulation that words have. Therefore, one could argue that it is impossible to analyze pictures with the help of a linguistic model.

How about congruence? Can a word correspond to a picture? Pictures are often conceived of as representing sentences rather than just words. Kress and van Leeuwen begin by calling visual composition a grammar from the outset, from page 1 on:

Just as grammars of language describe how words combine in clauses, sentences and texts, so our visual 'grammar' will describe the way in which people, places and things combine in visual 'statements' of greater or lesser complexity and extension. (Kress and van Leeuwen, 1996: 1)

Kress and van Leeuwen show some slight hesitation in using the word because it seems to refer to rules. They emphasize (1996: 12) that their approach to image analysis is different from the application of grammatical rules to verbal language, and present other concepts in their elaboration of visual composition. Surprisingly, they claim that "...we do not import the theories and methodologies of linguistics into the domain of the visual" (p. 17, 23). Hence, they (1996: 44) point out some differences: language consists of "action verbs". The corresponding element in pictures is called a vector. This preserves a parallel between the verbal and the visual, allowing both to be languages. Kress and van Leeuwen (p. 48) conceive of pictures as being able to say (at least some of) the same things as verbal language, but by very different means. There are the nouns and verbs of verbal language, on the one hand, and vectorial relations between volumes in pictures, on the other. The authors draw this parallel from linguistics to the analyses of visual quality. They are transcoding from verbal language to analyses of a picture. 
Kress and van Leeuwen (1996) borrow an approach and many key terms from linguistics and literary studies, such as grammar, code, visual literacy, and reading. One of their examples (1996: 21) consists of a short text and a drawing of a bathroom in a book. In their analysis, the picture is treated as if it were a verbal text. The authors make no attempt to conceive of the illustration as a visual image, which is a printed drawing in a book. This seems astonishing, considering that the aim is to focus on and clarify visual communication. Instead, they say that language comes first, because the accompanying text is placed on the left hand side in the layout of the book, "... authoritatively imposing meaning on the image..." This argument is followed by a more serious claim (p. 23): the drawing could be replaced by other pictures of bathrooms without too much loss of meaning. For someone interested in analyzing visual qualities, this is really stunning. It seems to contradict the claim that the picture is a statement with a style and also Kuusamo's conception of an image as unique occurrence (hapax). Pictures are subordinate to style; hence, the drawing of the bathroom functions as a specific stylistic expression and communicates a specific kind and atmosphere of a bath and a room, and it cannot be replaced by another picture without these being altered too. The significant choice of picture to illustrate their example (or a possible alternative) is not reflected upon, nor do they discuss what kind of bathroom is represented in the drawing and why. The actual choice, however, is significant from the point of view of interpreting actual visual characteristics.

Kress and van Leeuwen (1996) also discuss a very complex issue: the communicative process. Their starting point is the conception wherein someone produces a sign, which is then received or reproduced by someone else. This basic assumption - one which has been discussed extensively and would need some elaboration - is not problematized by the authors. Indeed, a relation exists between someone who interprets, and hence produces a sign, and an object, be it a verbal text or a picture. However, this does not necessary entail a theoretical configuration with a sender and a receiver, as in the model derived from information theory, which the authors refer to in their book (p. 46).

One very interesting aspect in interpretation of pictures lies in the relationship between materiality and meaning. Kress and van Leeuwen (1996: 231) discuss the process of inscription (i.e. the materialization or realization of texts in, say, brushstrokes). This is significant "particularly because it is in the process of inscription that unsemiotized materiality is drawn into semiosis." A design researcher may step back in wonder at this point, because in design the material is semiotized right from the start, or before even design started. The choice of material(s) always affects the outcome, the technology and the tools. In fact, for a designer, no unsemiotized material exists in the first place. A material functions as a sign before the very first line is drawn, be it on paper or on a computer screen. This situation is yet another difference between verbal language and pictures (or design products).

According to Kress and van Leeuwen there are similarities, but also many differences, between the verbal and the visual. However, by applying an approach drawn from linguistic theory to the analysis of visual matters they seem to create insoluble problems from the outset, as discussed above. Thus their approach does not seem helpful for design studies.

\section{Discussion}

What are the consequences of the comparison to verbal language for design? One may ask whether the concept of text in all its modified broadness is fruitful or even suitable for all modes of expression and signification; also, how about the much-used term of form language (or product language)? In their book, Kress and van Leeuwen (1996) point at many important differences between verbal language and pictures, yet they do not reflect on their basic assumptions and the primacy of verbal language. This certainly justifies the questions posed in the beginning of this paper. 
In the present paper, I have discussed a few themes to begin with and looked at two books in these contexts. The purpose has been to draw attention to their way of dealing with visual analyses and design. Moreover, I wished to point at similar sayings in routine talk in the design world, which are used without much reflection on the problematic concerning the verbal and the visual.

In his helpful Handbook of Semiotics, Winfried Nöth (1995: 450) concludes, from a discussion of the semiotic autonomy of the picture, that language is needed for image analysis as an instrument, but verbal metalanguage must not be projected onto a visual object. It is my view that analyses of visual subject matter, therefore, need formulations based on the visual mode and its specific capacities and qualities. Interpretation could start out from visual perception, its specificity vis-à-vis its object, and concepts need to be clarified accordingly. Then, inspiring concepts can indeed be adopted from, for instance, linguistics. The concept of metonymy seems to be helpful for visual analysis, as exemplified by Barthes in his Rhetoric of the Image (1964). Kress and van Leeuwen (1996), however, dismiss its possibilities. They conceive of their examples in terms of symbols instead of the powerful metonymic relation (pp. 109-110). The character and style of pictorial composition and the structuring of a space with elements are influenced by metonymic relations. Metonymy can be understood, in this context, not as a mere direct application of linguistics, but would need explicit modification in a visual context. With this statement, I would like to suggest the topic to be studied further with a view to clarification of key concepts in visual design.

\section{Susann Vihma}

Professor, Doctor of Arts

Aalto University School of Arts, Design and Architecture

Email address: susann.vihma@aalto.fi

\section{References}

Barthes, R. (1964). Rhetoric of the Image. In R. Barthes, (1977), Image, Music, Text. (pp.3251). New York: Noonday Press.

Baudrillard, J. (2003) Cool Memories IV. London: Verso.

Gros, J. (1983) Grundlagen einer Theorie der Produktsprache. (handout) Hochschule für Gestaltung Offenbach am Main.

Kress, G. \& van Leeuwen, T. (1996) (reprinted twice 2001). Reading Images: the Grammar of Visual Design. New York: Routledge.

Krippendorff, K. (2006). The Semantic Turn, a New Foundation for Design. Boca Raton: Taylor \& Francis.

Kuusamo, A. (1986). Sanooko kuva, kuvaako sana? [Does an image speak, does a word depict?] In A. Kuusamo, (1990), Kuvien edessä. (pp.73-82). Helsinki: Gaudeamus.

Lotman, J. (1981). Kulttuurisemiotiikka ja tekstin käsite [Cultural Semiotics and the Concept of Text]. In J. Lotman, Merkkien maailma - kirjoitelmia semiotiikasta. (1989, pp.149156). Helsinki: SN-kirjat.

Munch, A.V. (2003). Minimalismens logik. Eller de rene formers poetic hos Loos, Wittgenstein og Mies van der Rohe [The Logic of Minimalism. Or the Poetic of Pure Form by Loos, Wittgenstein and Mies van der Rohe]. In Nordisk Arkitekturforskning 2. Århus: Nordisk förening för arkitekturforskning. 
Nöth, W. (1995). Handbook of Semiotics. Bloomington: Indiana University Press.

Shove, E., Watson, M., Hand, M. \& Ingram, J. (2007). The Design of Everyday Life. Oxford: Berg.

Sonesson, G. (2003). Resurserna i språkets och bildens semiotik - från Lessing till Kress \& van Leeuwen [Resources in Semiotics of Language and Pictures - from Lessing to Kress \& van Leeuwen]. In H. Lönnroth, (Ed.), Från Närpesdialekt till EU-svenska (2003, pp.225-258). Tampere: Tampere University Press.

Steveartgallery. REMBRANDT Harmenszoon van Rijn:. Double Portrait of Cornelis Claesz.Anslo and His Wife,Aeltje Gerritsdr Schouten. Retrieved June 18, 2012, from http://www.steveartgallery.se/sweden/picture/image-34468.html 